\title{
Ceramic-on-ceramic THA Implants in Patients Younger Than 20 Years
}

\author{
Didier Hannouche MD, PhD, Flore Devriese MD, Jérôme Delambre MD, \\ Frédéric Zadegan MD, Idriss Tourabaly MD, Laurent Sedel MD, \\ Sylvie Chevret MD, PhD, Rémy Nizard MD, PhD
}

Received: 4 April 2015/Accepted: 26 August 2015/Published online: 4 September 2015

(C) The Association of Bone and Joint Surgeons (B) 2015

\begin{abstract}
Background Poor survival of THA implants in very young patients has been attributed to use of cemented implants, wear of conventional polyethylene, and the presence of morphologic deformities in the proximal femur or in the acetabulum. Few studies have reported the longterm results of ceramic-on-ceramic implants in THAs in patients younger than 20 years.

Question/purposes We determined: (1) the proportion of patients who experienced complications related to the ceramic bearing (squeaking, fracture); (2) the survivorship free from loosening and free from revision for any reason; (3) whether patients with osteonecrosis had inferior survivorship compared with patients whose surgical indication
\end{abstract}

Three authors certify that they (DH, LS, RN) have received payments or benefits, during the study period, an amount of USD 10,000 to USD 100,000, from Ceraver-Osteal (Roissy, France).

All ICMJE Conflict of Interest Forms for authors and Clinical Orthopaedics and Related Research ${ }^{\mathbb{R}}$ editors and board members are on file with the publication and can be viewed on request. Clinical Orthopaedics and Related Research ${ }^{\mathbb{R}}$ neither advocates nor endorses the use of any treatment, drug, or device. Readers are encouraged to always seek additional information, including FDA approval status, of any drug or device before clinical use.

Each author certifies that his institution approved the human protocol for this investigation, and that all investigations were conducted in conformity with ethical principles of research.

This study was performed at Hôpital Lariboisière, Paris, France.

D. Hannouche ( $\varangle)$, F. Devriese, J. Delambre, F. Zadegan,

I. Tourabaly, L. Sedel, R. Nizard

Department of Orthopaedic Surgery and Traumatology, AP-HP,

Hôpital Lariboisière, Université Paris 7 Denis Diderot, 2 Rue

Ambroise Paré, 75010 Paris, France

e-mail: didier.hannouche@1rb.aphp.fr;

didier.hannouche@gmail.com was all other diagnoses including sequelae of pediatric hip disorders (developmental dysplasia of the hip, Legg-CalvéPerthes disease, slipped capital femoral epiphysis); and (4) clinical function.

Methods Between 1979 and 2013, we performed 113 primary THAs in 91 patients younger than 20 years at the time of surgery. Of those, 105 THAs (83 patients) were done with ceramic-on-ceramic bearings ( $91 \%$ of the 91 patients); during that period, a ceramic-on-ceramic bearing couple was indicated in all patients younger than 20 years. In eight patients (eight hips), a cemented polyethylene cup was implanted because the diameter of the acetabulum was smaller than the smallest available ceramic cup $(46 \mathrm{~mm})$, or because adequate fixation of a ceramic press-fit cup could not be achieved despite careful reaming of the acetabulum. The most common diagnosis indicating THA was avascular necrosis of the femoral head $(56.2 \%$; 59 hips). Thirty-five patients (40 hips) had undergone previous operations before the replacement. Three patients (4\%; four hips) died from unrelated causes, nine patients $(11 \% ; 13$ hips) were lost to followup, and four patients (five hips) had a followup greater than 8.5 years but have not been seen in the last 5 years. Patients were assessed clinically (using the Merle d'Aubigne-Postel score, Hip disability and Osteoarthritis Outcome score (HOOS), and the SF-12 ${ }^{\mathbb{R}}$ Health Survey, and radiographically for signs of radiolucencies, subsidence, or osteolysis on plain films. The mean followup was $8.8 \pm 6.1$ years (range, 2-34.4 years).

\section{S. Chevret}

Department of Biostatistics and Medical Informatics, AP-HP, Hôpital Saint Louis, Université Paris 7 Denis Diderot, Paris, France 
Results Five patients experienced transient noise generation, defined as a snap in four patients and squeaking in one. Seventeen hips underwent revision surgery-16 for aseptic loosening and one for septic loosening. The implant survival rate at 10 years with aseptic loosening as the endpoint was $90.3 \%$ (95\% CI, 82.4\%-98.9\%). No hip had acetabular or femoral osteolysis. Survivorship in patients with osteonecrosis did not differ from survivorship in patients with other diagnoses. The Merle d'Aubigne-Postel score increased from $10.1 \pm 4.0$ to $17.6 \pm 1.1(\mathrm{p}<0.01)$; the mean HOOS score was $79.3 \pm 13.8$ (range, 50.6-100); the mean SF-12 ${ }^{\circledR}$ physical and mental component scores were $48.1 \pm 7.9$ (range, 21.4-57.6), and $47.4 \pm 12.2$ (range, 24.5-99.4), respectively.

Conclusions We found that patient-reported outcomes scores improved in most patients undergoing THA in this very young study group. Underlying diagnosis did not affect long-term survivorship. However, the revision-free survival rate at 10 years is lower than published estimates in older patients, and with $11 \%$ of patients lost to followup, our estimates may represent a best-case scenario. Therefore, we believe THA should be performed as a last resort in this population.

Level of Evidence Level IV, therapeutic study.

\section{Introduction}

THA is a highly successful surgery, referred to as "the operation of the century" in 2007 [28]. The number of THAs performed is expected to increase markedly among all age groups in the coming years, especially in young patients [26]. High success rates obtained in the general population, in concert with improvements in surgical techniques, component designs, and biomaterials have stimulated the demand for THA in very young and active patients who want to participate in typical activities of their healthy peers. However, many surgeons are reluctant to perform THAs in young adults because the population has been long considered at higher risk for revision surgery than the elderly population [27, 33, 38, 39, 44]. Adelani et al. [1] reported that earlier studies evaluated mainly results of THA in patients with juvenile rheumatoid arthritis and the use of cemented implants and conventional polyethylene that potentially contributed to component failure. In addition, the presence of morphologic deformities in patients who have undergone previous femoral or pelvic procedures in childhood may make THAs in these patients more difficult, more complicated, or less durable.

During the last decade, alternative bearings have been developed, including highly cross-linked polyethylene and hard-on-hard bearings, with the potential to reduce wear and extend implant longevity in younger, more-active patients. Ceramic-on-ceramic bearing couples have become an alternative to standard surface bearing couples (such as metal-on-polyethylene) because of decreased wear production and lower rates of osteolytic lesions compared with metal-on-conventional polyethylene [21]. The results of modern ceramic-on-ceramic bearings are available in patients younger than 60 years who have degenerative diseases [2, 3, 16, 29, 30], but few reports [6, 15, 23] have focused on patients younger than 20 years, who may be more likely to have high activity levels, perform sports activities, or engage in higher-demand workplace tasks.

The purpose of our study therefore was to evaluate the functional and radiographic results of patients younger than 20 years who had a ceramic-on-ceramic implant placed during THA. We determined: (1) the proportion of patients who experienced complications related to the ceramic bearing (squeaking, fracture); (2) the survivorship free from loosening and free from revision for any reason; (3) whether patients with osteonecrosis had inferior survivorship compared with patients whose surgical indication was all other diagnoses including sequelae of pediatric hip disorders (developmental dysplasia of the hip, Legg-CalvéPerthes disease, slipped capital femoral epiphysis), infection, and juvenile rheumatoid arthritis; and (4) clinical function based on the Merle d'Aubigne-Postel score, Hip disability and Osteoarthritis Outcome score (HOOS), and the SF-12 ${ }^{\circledR}$ Health Survey.

\section{Patients and Methods}

Between January 1979 and January 2013, we identified 91 patients (113 hips), who had a THA at our institution and were younger than 20 years at the time of surgery. Of the 113 THAs, 105 (83 patients) were done with ceramic-onceramic bearings (in $91 \%$ of the patients younger than 20 years); during that period, a ceramic-on-ceramic bearing couple was indicated in all patients younger than 20 years. In eight patients (eight hips), a ceramic-on cemented polyethylene cup bearing was implanted because (1) the diameter of the acetabulum was smaller than the smallest available ceramic cup (46 mm), or (2) because adequate fixation of a ceramic press-fit cup could not be achieved despite careful reaming of the acetabulum. Three senior surgeons (LS, RN, DH) performed all surgeries. There were 42 female $(50.6 \%)$ and 41 male $(49.4 \%)$ patients, with a mean age at the time surgery of $17.3 \pm 1.9$ years (range, 13.2-20.0 years). Mean patient weight was $54.0 \pm 12.2 \mathrm{~kg}$ (range, 40-85 kg), and the mean height was $161.9 \pm 7.7$ $\mathrm{cm}$ (range, 132-182 cm). Twenty-two patients had a bilateral, one-stage surgical procedure. 
Underlying diagnoses were avascular femoral head necrosis in 59 hips (56\%), sequelae of slipped capital femoral epiphysis in 12 hips $(11 \%)$, postinfection osteoarthritis in 11 hips (11\%), osteoarthritis secondary to hip dysplasia in 11 hips (10\%), sequelae of Legg-Calvé Perthes disease in five hips $(5 \%)$, inflammatory disease in five hips (5\%), and idiopathic chondrolysis in two hips $(2 \%)$. For the 59 hips with osteonecrosis $(56 \%)$, the associated etiologic factors included chemotherapy and bone marrow allografting (21 hips; 20\%), steroid therapy (13 hips; $12 \%$ ), posttraumatic disease (nine hips; 9\%), sickle cell disease (nine hips; 9\%), and idiopathic osteonecrosis (seven hips; 6\%) (Table 1). Thirty-five patients (40 hips) had undergone previous surgery before THA, including pin or screw femoral neck fixation (19 hips), decompression procedure for femoral head necrosis (two hips), septic hip arthrotomy (three hips), pelvic osteotomy (two hips), femoral osteotomy (four hips), and pelvic and femoral osteotomies (two hips) (Table 2).

For THA, we used a posterior approach in 98 hips and a direct lateral approach with trochanteric osteotomy in seven hips. All patients received surgical-grade aluminaon-alumina combination implants. During the 34-year period, we used five different types of sockets by CeraverOsteal (Roissy, France). A cemented monoblock alumina socket was implanted in two hips, a press-fit plain alumina socket in one hip (Cerapress ${ }^{\mathbb{R}}$ ), a titanium alloy, smooth screw-in ring with an alumina insert in one hip, a fibermesh metal back with an alumina insert in 11 hips (Cerafit ${ }^{\mathbb{R}}$ ), and a hydroxyapatite (HA)-coated titanium metal back with an alumina insert (Cerafit-HA ${ }^{\mathbb{R}}$ ) in 90 hips. Adjunctive acetabular screws were used at the surgeon's discretion to achieve initial mechanical stability. Acetabular reconstruction using the femoral head was necessary in three hips. Thirty-one hips (30\%) had a cemented titanium

Table 1. Underlying diagnoses

\begin{tabular}{ll}
\hline Initial diagnosis leading to THA & $\begin{array}{l}\text { Number of hips } \\
(\mathrm{n}=105)\end{array}$ \\
\hline Avascular necrosis of the femoral head & 59 \\
Allogenic bone marrow transplantation & 21 \\
Steroid-induced & 13 \\
Trauma & 9 \\
Sickle cell disease & 9 \\
Idiopathic & 7 \\
Slipped capital femoral epiphysis & 12 \\
Developmental dysplasia of the hip & 11 \\
Sequelae of Legg-Calvé-Perthes disease & 5 \\
Sequelae of hip infection & 11 \\
Juvenile rheumatoid arthritis & 5 \\
Idiopathic chondrolysis & 2
\end{tabular}

alloy stem, and 74 (70\%) received a fully hydroxyapatitecoated tapered cementless stem, beginning in 1997. After 1997 , a cemented stem was used only in very narrow femurs that required femoral reaming. Femoral reaming was necessary in 11 hips to fit the smallest standard-sized cemented implant. Cement always was used with a secondgeneration technique. The bone was cleaned thoroughly before cement insertion, an intramedullary plug was used, and the cement was inserted retrograde to reduce the voids and lamination in the cement mantle. Femoral head size varied between $28 \mathrm{~mm}$ (for 46- and 48-mm cups) and 32 $\mathrm{mm}$. Postoperatively, patients were mobilized the day after surgery with in-hospital physical therapy. Partial weightbearing was allowed with use of two crutches for 6 weeks. Twenty-seven patients (32 hips) who had substantial preoperative stiffness needed formal physiotherapy.

All patients were followed clinically and radiographically at 6 weeks, 6 months, and 1 year postoperatively, and were evaluated at the latest followup by an independent surgeon (FD), who did not participate in patient care. The mean followup was $8.8 \pm 6.1$ years (range, 2-34.4 years). Three patients (4\%; four hips) died of unrelated causes at a mean 123 months (range, 118-150 months) after surgery; none of the deaths were related to the THA. At the last documented followup, there had been no failures in the four hips. Nine patients $(11 \% ; 13$ hips) were considered lost to followup, as they could not be located despite telephone calls and Internet searches. In addition to these patients, four patients (five hips) had a followup greater than 8.5 years but had not been seen during the last 5 years. When patients were unable to return for face-to-face assessment and radiographic followup, they were

Table 2. Previous surgeries

\begin{tabular}{ll}
\hline Surgery & Hips $(\mathrm{n}=105)$ \\
\hline No previous surgery & 65 \\
Number of previous surgeries (number of patients) & $40(35)$ \\
1 surgery & $24(22)$ \\
2 surgeries & $9(7)$ \\
3 surgeries & $5(4)$ \\
4 surgeries & $2(2)$ \\
Previous surgery & 40 \\
Pin or screw fixation & 19 \\
Decompression procedure (osteonecrosis) & 2 \\
Septic hip arthrotomy & 3 \\
Femoral osteotomy & 4 \\
Pelvic osteotomy & 2 \\
Femoral and pelvic osteotomy & 2 \\
Epiphysiodesis & 1 \\
Miscellaneous & 7 \\
\hline
\end{tabular}


interviewed by telephone to obtain clinical outcome data and information regarding any complications and reoperations. Patients (six patients; eight hips) interviewed by telephone were asked to mail in followup questionnaires and to send recent radiographs. Overall, 71 patients $(88$ hips) were analyzed with a minimum followup of 2 years. The actual followup was 8.8 years (range, 9 months-34 years), whereas the potential median followup was 13.7 years (range, 5.6-39.3 months). To better show our data, we used a Kaplan Meier curve showing, on the x-axis, the number of patients followed up with time. At 5 years $(60$ months) after the surgery, 55 patients (72 hips) were still being followed up (Fig. 1). Thus, 28 patients (33 hips) had a followup less than 5 years.

Clinical evaluation included physical examination and the Merle d'Aubigne-Postel score [11]. All patients were asked to complete the HOOS questionnaire [32] and the SF-12 ${ }^{\circledR}[43]$. The SF- $122^{\circledR}$ is a shortened version of the SF$36^{\circledR}$ Health Survey, which generates a mental component score and physical component score. The scores reflect overall health-related quality of life. All patients were surveyed regarding their ability to return to their occupational activities and perform sports activities. To obtain the proportion of squeaking hips, all patients were asked specifically about any noise from the surgically treated hip. They were asked to describe the noise. If present, the squeaking - which is a high-frequency noise analogous to that heard from a nonlubricated hinge-then was further characterized by onset time, intensity (audibility by others nearby), frequency, and activities that generated the squeak (bending, walking, rising from chair).
One of us (FD) independently reviewed standardized AP pelvic radiographs taken preoperatively and at the latest followup. On the socket side, we examined the radiographs for radiolucent lines and osteolysis according to DeLee and Charnley zones [12]; aseptic loosening of the socket was defined as a change in the opening angle of the socket greater than $4^{\circ}$, cup migration greater than $4 \mathrm{~mm}$ in either the vertical or horizontal position in relation to the teardrop, and/or the presence of a radiolucent line greater than $2 \mathrm{~mm}$ at the metal-bone interface around its entire circumference. On the femoral side, the radiographs were examined for radiolucent lines and osteolysis in the seven zones of Gruen et al. [20], and the distance between the collar of the prosthesis and the lesser trochanter and between the vertical distance from the tip of the greater trochanter to the distal tip of the implant were measured. A difference greater than $4 \mathrm{~mm}$ between radiographs on both measurements was required to establish subsidence.

Qualitative data were expressed as counts and percentages in groups, and quantitative data by mean \pm SD. Qualitative data (gender, preoperative diagnosis) were compared using the chi-square test or Fisher's exact test. For quantitative data (Merle d'Aubigne-Postel score, inclination angle of the acetabulum), we determined differences between pre- and postoperative values using the t-test and the Mann-Whitney test, depending on the distribution of the data. Survivorship analysis was performed on the entire cohort of 105 hips and on the entire cohort of 83 patients, evaluating the time to first revision for any reason and for aseptic loosening of either component. The survival curve was derived from the cumulative survival
Fig. 1 The point estimates with 95\% CIs in the whole sample of 105 hips are shown. The revisionfree rate at 10 years was estimated at $90.3 \% \quad(95 \% \quad \mathrm{CI}, \quad 82.4 \%$ $98.9 \%$ ). The numbers on the $\mathrm{x}$-axis represent the number of patients followed up with time.

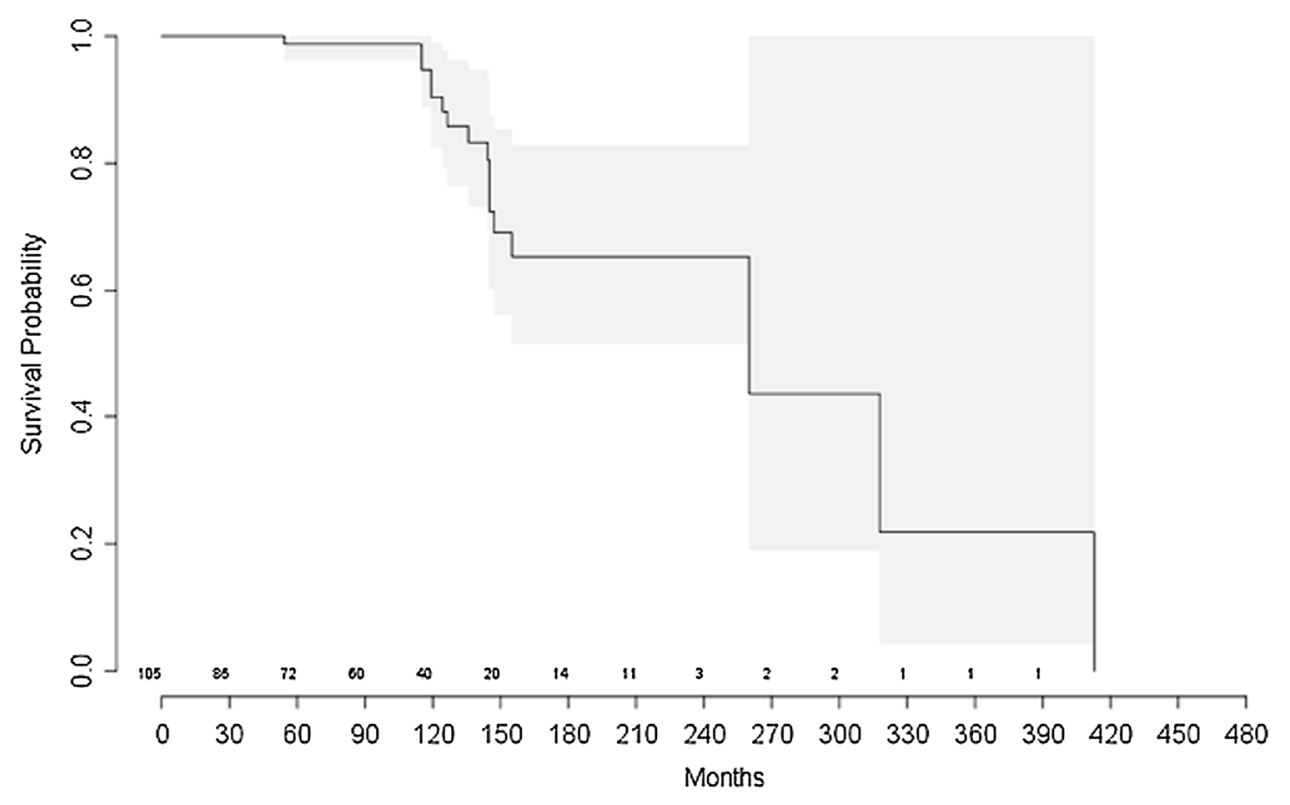


rate with time calculated from the actuarial life table and Kaplan-Meier method. This allows consideration of the actual different followups of the patients, resulting in rightcensored observations. The standard error was estimated by Greenwood's formula, with derivation of the $95 \%$ CIs for each survival rate. Comparison of survival curves was performed using the log-rank test. We compared the revision-free survival according to diagnoses (segregating the avascular necroses from the others), age at intervention, gender, and the type of cup implanted (distinguishing the Cerafit-HA ${ }^{\circledR}$ cup from the others). We used StatView ${ }^{\circledR}$ 5.0 software (SAS ${ }^{\circledR}$ Institute, Inc, Cary, NC, USA) and R (http://www.R-project.org/) for all statistical analyses [19].

\section{Results}

Early complications included one hematoma, one subluxation which did not recur in a patient suspected of having Marfan syndrome, and one unrelated supracondylar fracture that occurred 1 year later. Five of the 71 patients (71\%) experienced transient noise generation, defined as a snap in four patients and squeaking in one. The noise was painless and self-resolved in all patients without surgical intervention. No dislocations or alumina component fractures were observed in these patients.

The median followup was 8.8 years (range, 9 months-34 years). During this followup, a total of 17 hips were revised, with a revision-free rate at 10 years estimated at 90.3\% (95\% CI, 82.4\%-98.9\%) and a median time to revision of 21.7 years (Fig. 1). Sixteen hips were revised for aseptic loosening (13 patients) and one for septic loosening. In this series, all loose prostheses were revised. Fourteen revisions were performed for isolated acetabular loosening, one for acetabular and femoral loosening, and one for isolated femoral loosening. Revision surgery was performed at a mean $64.9 \pm 67.2$ months (range, 7-223 months) after the index surgery. The hazard of revision was modified by age at intervention, with a median time to revision of 12.9 years in patients younger than 17 years, versus 26.5 years in patients older than 17 years $(\mathrm{p}=0.018)$ (Fig. 2A). In patients who had revision surgery, their average age at the time of the initial arthroplasty was 16.3 \pm 1.7 years. There were 13 observed failures among the 90 Cerafit-HA ${ }^{\circledR}$ cups, versus four among the 15 other cups ( $p$ $=0.0465$ by the log-rank test) (Fig. 2B). There were no differences according to sex $(p=0.71)$ or previous surgery $(p=0.44)$. In addition, both estimates from the 105 hips, or the 83 patients (Fig. 3A), and the distribution of survival times free of hip revision regardless of cause, or in aseptic loosening, were similar (Fig. 3B). Three patients with avascular osteonecrosis of the femoral head, who had received bilateral hip arthroplasties, had bilateral loosening
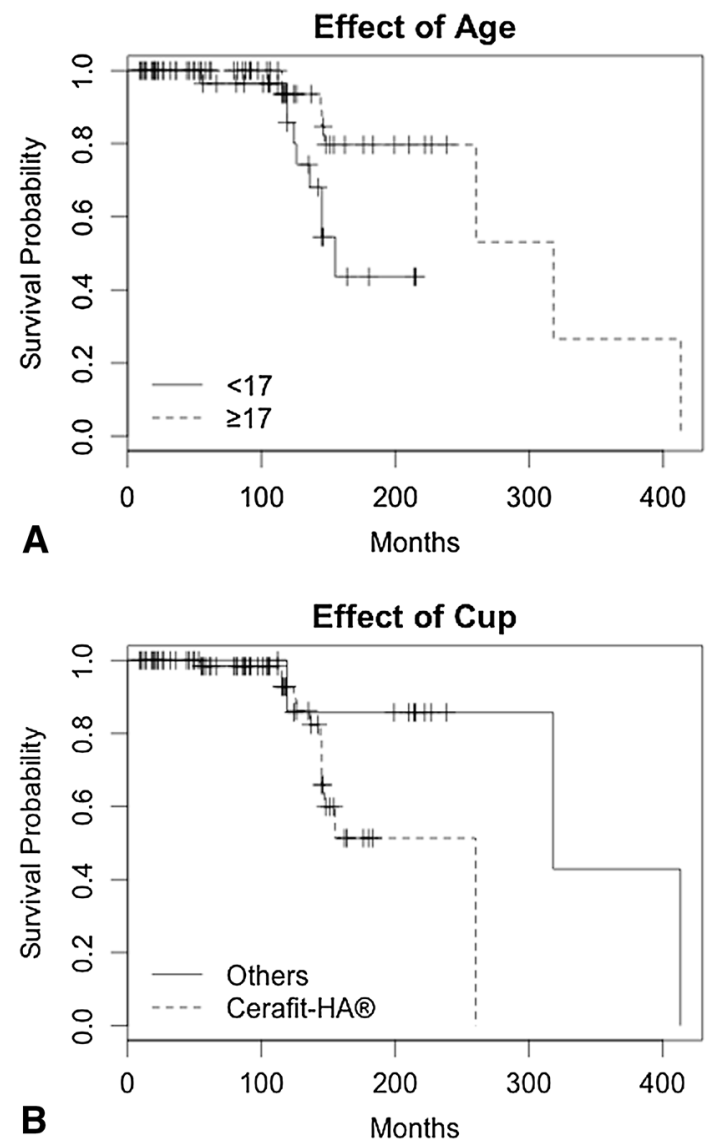

Fig. 2A-B The hazard of revision was modified by age at intervention and type of cup. (A) The survival free of revision for patients younger than 17 years or 17 years or older $(\mathrm{p}=0.018)$ is shown. $(\mathbf{B}) \mathrm{A}$ comparison of estimates based on the type of cup, Cerafit-HA ${ }^{\mathbb{R}}$ versus the others ( $p=0.0465$ by the log-rank test), is shown.

of the cups. However, the limited number of bilateral hips did not allow us to draw any conclusions on this group.

We compared the revision-free survival at 10 years according to diagnoses, segregating the patients with a diagnosis of avascular necrosis from the others. The underlying diagnoses for loosened hips was osteonecrosis in 11 hips (five idiopathic, three bone marrow allografting, two sickle cell disease, one posttraumatic); developmental hip dysplasia in two hips; slipped capital femoral epiphysis in two hips; and postinfectious arthritis in one. There was no difference at 10 years between revision-free survival in patients with osteonecrosis (90.6\%; CI, 84\%-97.2\%) and patients with other diagnoses $(86.8 \%$; 95\% CI, $80.6 \%$ $93 \%)(\mathrm{p}=0.60)$.

At the most recent followup, the mean Merle d'Aubigne-Postel score increased from $10.1 \pm 4.0$ to $17.6 \pm 1.1$ $(\mathrm{p}<0.01)$. Seventy-four patients returned to their occupational activities, and 46 patients were able to perform sports activities. At latest followup, the mean HOOS score 

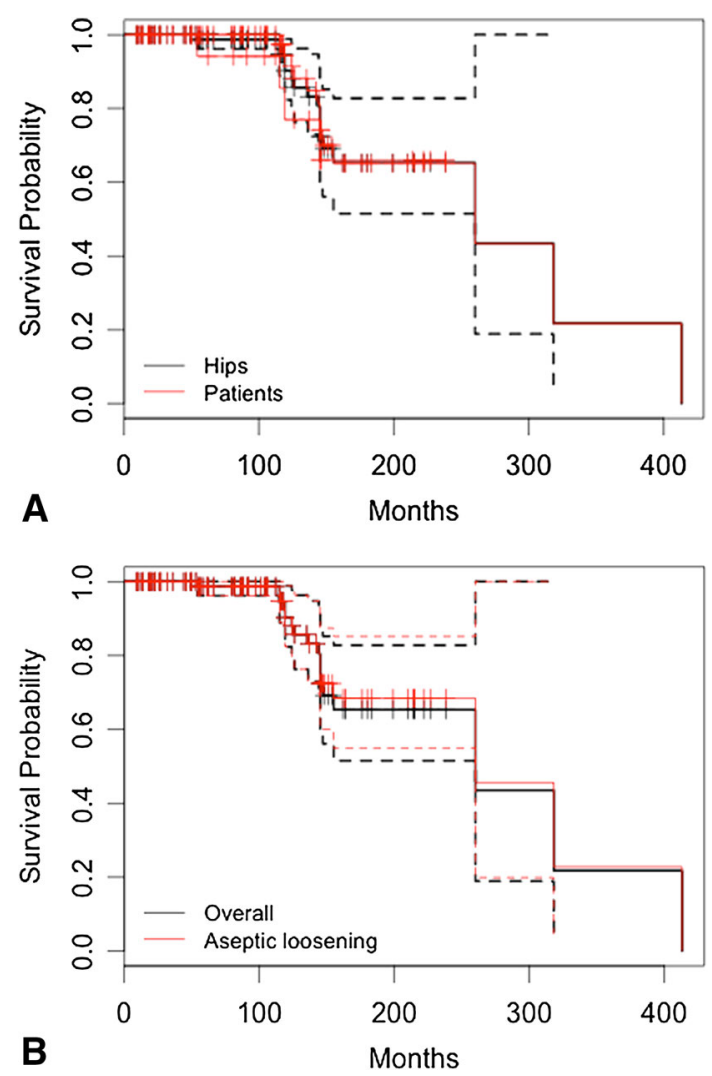

Fig. 3A-B (A) A comparison of estimates based on the total 105 hips (black curves) or on the 83 patients (red curves), and (B) the distribution of survival times free of hip revision regardless of cause (overall causes of revision; black curves), or in aseptic loosening (red curves), are shown.

was $79.3 \pm 13.8$ (range, 50.6-100) and mean physical and mental component scores were $48.1 \pm 7.9$ (range, 21.4-57.6), and $47.4 \pm 12.2$ (range, 24.5-99.4), respectively.

\section{Discussion}

The number of THAs is expected to increase among very young patients who wish to perform the typical activities of patients of the same age. The results of ceramic-on-ceramic bearings in patients who were older than 40 years have been reported [2, 3, 16, 29, 30], but few [6, 15, 23] have focused on the long-term results of ceramic-on-ceramic implants in patients younger than 20 years. In this series, we found the survivorship of ceramic-on-ceramic implants in adolescent patients was encouraging, averaging $90.3 \%$ at 10 years. An underlying diagnosis of osteonecrosis or a history of prior intervention did not affect long-term survival.
Our study has some limitations. First, an important limitation of our study concerns diagnostic heterogeneity of the sample of patients. In addition to osteonecrosis, the number of patients in each subgroup was limited, therefore it is difficult to draw definitive conclusions from our comparative subgroup survivorship analysis. Second, the study involved different component materials, qualities, and designs of implants, especially on the socket side, some of which no longer are used. However, the majority (90 hips) of patients received a HA-coated socket, which is still in use today. In addition, nine of our patients were lost to followup, and four have not been seen during the last 5 years, which might have resulted in overestimated survivorship and hip scores. Another limitation is the possibility of selection bias, as eight patients younger than 20 years (eight hips) had a ceramic-on-standard polyethylene bearing because of technical difficulties to implant a ceramic cup. Finally, CT scans would be more sensitive for osteolysis detection, but we believe CT scanning cannot be performed systematically given its cost and the risk of radiation exposure.

The frequency of complications related to the use of ceramic implants was low in our patients. There were no fractures of ceramic components. Five patients reported some transient noise (one squeak), but none underwent revision surgery for this problem. The proportion of patients reporting squeaking varies considerably, ranging from less than $1 \%$ to $20 \%$ [2, 24]. In a prospective observational study of 1486 ceramic-on-ceramic THAs, 95 hips (6\%) had squeaking develop [36]. Nine of the patients underwent revision surgery [36]. The prevalence of squeaking probably is underreported because the noise often is transient and patients are not specifically interviewed regarding this complication during followup consultations. Higher proportions of squeaking hips might be observed if patient-based questionnaires would be used [22]. The exact mechanism for squeaking remains unclear. Although several explanations have been proposed [7-9, $25,34,36,37,40,42]$, it is likely multifactorial. Femoral head microseparation owing to femoral neck impingement on an elevated metal rim may cause ceramic pullout, which was reported to be associated with a clicking sound [31]. Squeaking might be associated with excessive cup inclination or anteversion [41]. It was reported to be seven times higher for patients who had received a femoral stem with a narrower neck and made of titanium alloy material with lower stiffness [37]. Squeaking sometimes results in reoperations in cases of troublesome squeaking, ceramic fracture, severe malpositioning, or persistent pain. Patients who have received ceramic-on-ceramic bearings should be informed about this potential complication. 
Earlier reports of conventional metal-on-polyethylene bearings have shown relatively poor results and high rates of loosening in patients younger than 30 years, with some failure rates as much as $45 \%$ to $54 \%$ at 9-to- 15 years followup [13, 39]. In our study, 17 hips were revised, 16 of which were for aseptic loosening. Finkbone et al. [15] reported the results of 24 THAs with ceramic-on-ceramic implants in patients followed for an average of 52 months. They had only one revision for a loose acetabular component. In the study by Byun et al. [6], 41 patients younger than 30 years received cementless third-generation ceramic-on-ceramic implants for osteonecrosis of the femoral head. At a mean 7.7 years followup, no loosening of the femoral stem or acetabular cup was evident, and no patient underwent revision surgery. Similar results were reported in a series of 21 THAs; the patients had an average followup of 49 months [23]. The authors reported no radiographic loosening was seen and one hip was revised for a cracked ceramic liner [23]. No sign of osteolysis in the patients were reported in any of these studies. In our study, osteolysis could not be detected on AP radiographs in any patient at final followup. The limited occurrence of osteolytic lesions observed with ceramic-on-ceramic bearing couples is thought to be attributable to a lower concentration of wear particles in the periprosthetic tissue around the bearing [4].

Some authors have suggested that higher rates of failures in the patients younger than 20 years were more likely attributable to the underlying cause of hip dysfunction rather than young age, especially in the case of developmental dysplasia and inflammatory arthritis [17]. In our study, the underlying diagnosis was mainly chemotherapy or steroid-induced osteonecrosis in $56 \%$ of the hips. With the numbers available, survivorship data at the most recent followup were not different between patients with osteonecrosis and patients with other diagnoses. Similar results were reported in patients who received THA after pediatric hip diseases, such as developmental dysplasia of the hip, Legg-Calvé-Perthes disease, and slipped capital femoral epiphysis [14, 18]. Using merged individual-based data from the Nordic Arthroplasty Register Association, Engesaeter et al. [14] compared the survival of primary THA performed in patients with developmental dysplasia, slipped capital femoral epiphysis, Perthes' disease, or primary osteoarthritis; 14,403 THAs $(3.9 \%)$ were performed for sequelae of pediatric hip diseases. At 10 years followup, using the Kaplan-Meier method, survivorship was 93.6\% for THA in pediatric hip diseases, which was not different than survivorship after THA for osteoarthritis (93.8\%) after adjustment for differences in sex and age of the patients and for fixation method of the prostheses. An analysis of the New Zealand Joint Registry showed similar findings in patients with slipped capital femoral epiphysis undergoing THA [5]. Boyle et al. [5] identified 117 patients and compared them with 40,589 patients with primary osteoarthritis. There was no difference in the proportion of patients undergoing revision between the two groups.

Our study showed that young patients undergoing hip replacement had improved function after surgery. A systematic review of THA performed in patients 30 years or younger found that clinical results improved little after surgery and did not differ during the past two decades compared with historical controls [1]. Adelani et al. [1] stated that limited improvement in pain and function in these patients might be explained by poor overall health status and underlying systemic diseases; however, most of the studies included in our review focused on cemented THA for treating patients with juvenile rheumatoid arthritis, a situation less likely to occur today with the introduction of modern antirheumatic drugs. Clohisy et al. [10] reported on the function of 88 patients (102 hips) who had THAs and were 25 years or younger at the time of surgery. Only $12 \%$ of the patients had juvenile rheumatoid arthritis. At a mean 5 years followup, they observed (as in our study), major functional improvement in patients, with a mean Harris hip score increasing an average 40 points after surgery. Others have reported similar improvements in hip function and relief of pain after THA in this young population [15, 35].

We found that patient-reported outcomes scores improved in most patients undergoing THA in this very young study group. With the numbers available, the diagnosis of osteonecrosis or a history of prior procedures on the hip did not appear to affect long-term survivorship of THA bearings. However, because revision-free survival at 10 years appears to be lower than published estimates in older patients, and because, with $11 \%$ of patients lost to followup, our estimates may represent a best-case scenario, THA in very young and active patients should be considered with caution and should be performed as a last resort.

\section{References}

1. Adelani MA, Keeney JA, Palisch A, Fowler SA, Clohisy JC. Has total hip arthroplasty in patients 30 years or younger improved? A systematic review. Clin Orthop Relat Res. 2013;471:2595-2601.

2. Baek SH, Kim SY. Cementless total hip arthroplasty with alumina bearings in patients younger than fifty with femoral head osteonecrosis. J Bone Joint Surg Am. 2008;90:1314-1320.

3. Bizot P, Hannouche D, Nizard R, Witvoet J, Sedel L. Hybrid alumina total hip arthroplasty using a press-fit metal-backed socket in patients younger than 55 years: a six- to 11-year evaluation. J Bone Joint Surg Br. 2004;86:190-194.

4. Bohler M, Mochida Y, Bauer TW, Plenk H Jr, Salzer M. Wear debris from two different alumina-on-alumina total hip arthroplasties. J Bone Joint Surg Br. 2000;82:901-909. 
5. Boyle MJ, Frampton CM, Crawford HA. Early results of total hip arthroplasty in patients with slipped upper femoral epiphysis compared with patients with osteoarthritis. J Arthroplasty. 2012;27:1003-1007.

6. Byun JW, Yoon TR, Park KS, Seon JK. Third-generation ceramic-on-ceramic total hip arthroplasty in patients younger than 30 years with osteonecrosis of femoral head. J Arthroplasty. 2012;27:1337-1343.

7. Chevillotte C, Pibarot V, Carret JP, Bejui-Hugues J, Guyen O. Hip squeaking: a 10-year follow-up study. J Arthroplasty. 2012; 27:1008-1013.

8. Chevillotte C, Trousdale RT, An KN, Padgett D, Wright T. Retrieval analysis of squeaking ceramic implants: are there related specific features? Orthop Traumatol Surg Res. 2012;98: 281-287.

9. Chevillotte C, Trousdale RT, Chen Q, Guyen O, An KN. The 2009 Frank Stinchfield Award: "Hip squeaking": a biomechanical study of ceramic-on-ceramic bearing surfaces. Clin Orthop Relat Res. 2010;468:345-350.

10. Clohisy JC, Oryhon JM, Seyler TM, Wells CW, Liu SS, Callaghan JJ, Mont MA. Function and fixation of total hip arthroplasty in patients 25 years of age or younger. Clin Orthop Relat Res. 2010;468:3207-3213.

11. D'Aubigné RM, Postel M. Cotation chiffrée de la fonction de la hanche. Rev Chir Orthop Reparatice Appar Mot. 1970;56:481-486.

12. DeLee JG, Charnley J. Radiological demarcation of cemented sockets in total hip replacement. Clin Orthop Relat Res. 1976;121:20-32.

13. Dorr LD, Luckett M, Conaty JP. Total hip arthroplasties in patients younger than 45 years: a nine- to ten-year follow-up study. Clin Orthop Relat Res. 1990;260:215-219.

14. Engesaeter LB, Engesaeter IO, Fenstad AM, Havelin LI, Karrholm J, Garellick G, Pedersen AB, Overgaard S. Low revision rate after total hip arthroplasty in patients with pediatric hip diseases. Acta Orthop. 2012;83:436-441.

15. Finkbone PR, Severson EP, Cabanela ME, Trousdale RT. Ceramic-on-ceramic total hip arthroplasty in patients younger than 20 years. J Arthroplasty. 2012;27:213-219.

16. Garcia-Cimbrelo E, Garcia-Rey E, Murcia-Mazon A, BlancoPozo A, Marti E. Alumina-on-alumina in THA: a multicenter prospective study. Clin Orthop Relat Res. 2008;466:309-316.

17. Garcia-Rey E, Cruz-Pardos A, Garcia-Cimbrelo E. Alumina-onalumina total hip arthroplasty in young patients: diagnosis is more important than age. Clin Orthop Relat Res. 2009;467:2281-2289.

18. Gent E, Clarke NM. Joint Replacement for sequelae of childhood hip disorders. J Pediatr Orthop. 2004;24:235-240.

19. Gore SM. Assessing methods: survival. Br Med J (Clin Res Ed). 1981;283:840-843.

20. Gruen TA, McNeice GM, Amstutz HC. "Modes of failure" of cemented stem type femoral components: a radiographic analysis of loosening. Clin Orthop Relat Res. 1979;141:17-27.

21. Hannouche D, Zaoui A, Zadegan F, Sedel L, Nizard R. Thirty years of experience with alumina-on-alumina bearings in total hip arthroplasty. Int Orthop. 2011;35:207-213.

22. Jarrett CA, Ranawat AS, Bruzzone M, Blum YC, Rodriguez JA, Ranawat CS. The squeaking hip: a phenomenon of ceramic-onceramic total hip arthroplasty. J Bone Joint Surg Am. 2009;91: 1344-1349.

23. Kamath AF, Lee GC, Sheth NP, Nelson CL, Garino JP, Israelite CL. Prospective results of uncemented tantalum monoblock tibia in total knee arthroplasty: minimum 5-year follow-up in patients younger than 55 years. J Arthroplasty. 2011;26:1390-1395.

24. Keurentjes JC, Kuipers RM, Wever DJ, Schreurs BW. High incidence of squeaking in THAs with alumina ceramic-on-ceramic bearings. Clin Orthop Relat Res. 2008;466:1438-1443.
25. Kiyama T, Kinsey TL, Mahoney OM. Can squeaking with ceramic-on-ceramic hip articulations in total hip arthroplasty be avoided? J Arthroplasty. 2013;28:1015-1020.

26. Kurtz SM, Lau E, Ong K, Zhao K, Kelly M, Bozic KJ. Future young patient demand for primary and revision joint replacement: national projections from 2010 to 2030. Clin Orthop Relat Res. 2009;467:2606-2612.

27. Lachiewicz PF, McCaskill B, Inglis A, Ranawat CS, Rosenstein BD. Total hip arthroplasty in juvenile rheumatoid arthritis: two to eleven-year results. J Bone Joint Surg Am. 1986;68:502-508.

28. Learmonth ID, Young C, Rorabeck C. The operation of the century: total hip replacement. Lancet. 2007;370:1508-1519.

29. Lee YK, Ha YC, Yoo JJ, Koo KH, Yoon KS, Kim HJ. Aluminaon-alumina total hip arthroplasty: a concise follow-up, at a minimum of ten years, of a previous report. J Bone Joint Surg Am. 2010;92:1715-1719.

30. Lusty PJ, Tai CC, Sew-Hoy RP, Walter WL, Walter WK, Zicat BA. Third-generation alumina-on-alumina ceramic bearings in cementless total hip arthroplasty. J Bone Joint Surg Am. 2007;89: 2676-2683.

31. Nevelos J, Ingham E, Doyle C, Streicher R, Nevelos A, Walter W, Fisher J. Microseparation of the centers of alumina-alumina artificial hip joints during simulator testing produces clinically relevant wear rates and patterns. J Arthroplasty. 2000;15: 793-795.

32. Nilsdotter AK, Lohmander LS, Klassbo M, Roos EM. Hip disability and osteoarthritis outcome score (HOOS): validity and responsiveness in total hip replacement. BMC Musculoskelet Disord. 2003;4:10.

33. Nizard R, Pourreyron D, Raould A, Hannouche D, Sedel L. Alumina-on-alumina hip arthroplasty in patients younger than 30 years old. Clin Orthop Relat Res. 2008;466:317-323.

34. Owen D, Russell N, Chia A, Thomas M. The natural history of ceramic-on-ceramic prosthetic hip squeak and its impact on patients. Eur J Orthop Surg Traumatol. 2014;24:57-61.

35. Restrepo C, Lettich T, Roberts N, Parvizi J, Hozack WJ. Uncemented total hip arthroplasty in patients less than twenty-years. Acta Orthop Belg. 2008;74:615-622.

36. Restrepo C, Matar WY, Parvizi J, Rothman RH, Hozack WJ. Natural history of squeaking after total hip arthroplasty. Clin Orthop Relat Res. 2010;468:2340-2345.

37. Restrepo C, Post ZD, Kai B, Hozack WJ. The effect of stem design on the prevalence of squeaking following ceramic-onceramic bearing total hip arthroplasty. J Bone Joint Surg Am. 2010;92:550-557.

38. Sochart DH, Porter ML. Long-term results of cemented Charnley low-friction arthroplasty in patients aged less than 30 years. J Arthroplasty. 1998;13:123-131.

39. Torchia ME, Klassen RA, Bianco AJ. Total hip arthroplasty with cement in patients less than twenty years old: long-term results. J Bone Joint Surg Am. 1996;78:995-1003.

40. Walter WL, Kurtz SM, Esposito C, Hozack W, Holley KG, Garino JP, Tuke MA. Retrieval analysis of squeaking alumina ceramic-onceramic bearings. J Bone Joint Surg Br. 2011;93:1597-1601.

41. Walter WL, O'Toole GC, Walter WK, Ellis A, Zicat BA. Squeaking in ceramic-on-ceramic hips: the importance of acetabular component orientation. J Arthroplasty. 2007;22:496-503.

42. Walter WL, Waters TS, Gillies M, Donohoo S, Kurtz SM, Ranawat AS, Hozack WJ, Tuke MA. Squeaking hips. J Bone Joint Surg Am. 2008;90(suppl 4):102-111.

43. Ware J Jr, Kosinski M, Keller SD. A 12-Item Short-Form Health Survey: construction of scales and preliminary tests of reliability and validity. Med Care. 1996;34:220-223.

44. Witt JD, Swann M, Ansell BM. Total hip replacement for juvenile chronic arthritis. J Bone Joint Surg Br. 1991;73:770-773. 